\title{
Water management simulation games and the construction of knowledge
}

\author{
M. Rusca, J. Heun, and K. Schwartz \\ UNESCO-IHE Institute for Water Education, Department of Integrated Water Systems and Governance, P.O. Box 3015, \\ 2601 DA Delft, The Netherlands
}

Correspondence to: K. Schwartz (k.schwartz@unesco-ihe.org)

Received: 20 February 2012 - Published in Hydrol. Earth Syst. Sci. Discuss.: 12 March 2012

Revised: 13 July 2012 - Accepted: 18 July 2012 - Published: 16 August 2012

\begin{abstract}
"Knowledge will not come from teaching, but from questioning. He will recover it for himself" (Plato, 1956:135).
\end{abstract}

Abstract. In recent years, simulations have become an im-
portant part of teaching activities. The reasons behind the
popularity of simulation games are twofold. On the one hand,
emerging theories on how people learn have called for an
experienced-based learning approach. On the other hand, the
demand for water management professionals has changed.
Three important developments are having considerable con-
sequences for water management programmes, which edu-
cate and train these professionals. These developments are
the increasing emphasis on integration in water management,
the characteristics and speed of reforms in the public sec-
tor and the shifting state-society relations in many countries.
In response to these developments, demand from the labour
market is oriented toward water professionals who need to
have both a specialist in-depth knowledge in their own field,
as well as the ability to understand and interact with other
disciplines and interests. In this context, skills in negotiat-
ing, consensus building and working in teams are considered
essential for all professionals. In this paper, we argue that
simulation games have an important role to play in (actively)
educating students and training the new generation of water
professionals to respond to the above-mentioned challenges.
At the same time, simulations are not a panacea for learn-
ers and teachers. Challenges of using simulation games in-
clude the demands it places on the teacher. Setting up the
simulation game, facilitating the delivery and ensuring that
learning objectives are achieved require considerable knowl-
edge and experience as well as considerable time-inputs of
the teacher. Moreover, simulation games usually incorporate a case-based learning model, which may neglect or underemphasize theories and conceptualizations. For simulations to be effective, they have to be embedded in this larger theoretical and conceptual framework. Simulations, therefore, complement rather than substitute traditional teaching methods.

\section{Introduction}

Since the 1960s, simulations, together with games and other experience-based instructional methods, have increasingly gained popularity in teaching activities. The core idea of a simulation game is that it brings together elements of simulations (a real-life situation, event or activity is imitated) and games (players, rules, competition, co-operation). The use of these tools for pedagogical purposes was triggered by different drivers. On the one hand, the emergence of new theories on how people learn has promoted the use of simulation games in education. Pioneers (see for example Piaget, 1950; Dale, 1969) have promoted experiencedbased learning since the 1950s, but it is only since the 1980s that the idea of experienced-based learning has gained importance among different pedagogical and social schools (Niemi, 2002; Boekaerts et al., 2000; Simons, 1997 in Niemi, 2002, Bales, 1996; Gardner, 1991). Although diverse theories and perspectives on education and learning have surfaced over time, a consensus has emerged that "knowledge is created, rather than transferred" (Wright et al., 1994). Consequently, rather than passively digest knowledge conveyed by teachers, students should "actively engage in the experience" (Thomas and Milligan, 2004). This paradigm shift calls for a shift in teaching methods and tools to activate students. At 
the same time, the demands for graduates of water management programmes have changed over the past decades. Management at the level of the river basin has become "a central tenet of mainstream water policies anchored in the overarching concept of Integrated Water Resources Management" (Molle, 2009). The labour market requires a more multi- and interdisciplinary professional, endowed with skills such as negotiations, team-building and consensus-building.

In this paper, we argue that simulation games have an important role to play in this shift of teaching methods and the changing demands for water managers. We develop this argument by first elaborating on the shift in teaching methods and the role that simulation games can play in this shift. The second part of the article presents an elaboration on the changing demands placed on water managers (and as an extension also on educational programmes in water management). These changing demands result from the above-mentioned emphasis on IWRM, the increasingly rapid reforms occurring in the public sector and the need for coordination as a result of changing governance systems that incorporate a multitude of (semi-) autonomous agencies and actors. The third section presents the Ravilla simulation game and discusses the lessons learnt in implementing this game over the past decade.

\section{From transferring to constructing knowledge}

Historically, learning was associated with a transfer from a knowledgeable individual to a group of uneducated learners through books, lectures and articles. The traditional learning paradigm is effectively represented by Locke's notion of $t a b$ ula rasa, or "blank slate". The mind is seen as an empty container to be filled, rather than a muscle to be trained through exercises and challenges (Wright et al., 1994). The implications for teaching are many: everyone who "knows" can teach. The task of the teacher is to transfer knowledge to students who passively receive this knowledge. The relationship between teacher and student is rather impersonal and based on a clear hierarchy. The classroom is very much a competitive environment in which each student aims at outperforming classmates by reproducing as much of the transferred knowledge as possible (Wright et al., 1994).

\subsection{Early criticism to the concept of knowledge transfer}

Although traditional education methods have remained largely predominant in higher education, criticism and questions regarding our understanding of learning have long resonated. The constructivist theory, which dates back to Piaget's studies (1950 and later), was fundamental in raising these concerns and in fuelling the debate on learning methods for over half a decade. Constructivists argue that knowledge is constructed through the learners' own activities, "[...] building on what they already know". Teaching is not a mat- ter of transmitting but of [...] building their knowledge in terms of what they already understand" (Biggs and Tang, 2007). The debate shifted to methods, media and tools to allow learners to lead their own learning process. In 1969, Dale theorized that learners retain more information when they have to actively "do" something than when they passively hear or read something. As such, the amount of information retained by the learner is linked to the teaching methods used (Bales, 1996). In the 1990s, Dale's learning theory regained popularity and was further developed by placing numerical scores on the effectiveness (in terms of how people learn) of different teaching methods. According to Bale (1996), of a traditional lecture, only $5 \%$ of information provided is retained by the participant. Reading (10\% of information retained), audiovisual materials ( $20 \%$ of information retained) and demonstrations (30\% of information retained) are seen as more effective. Even more knowledge is retained in group discussions $(50 \%)$. The underlying suggestion of these different rates is that learning appears to be a fundamentally social process and, as such, requires an act of participation on behalf of the learner (Henshel, 1999). The most "successful" learning experiences occur with practical exercises $(75 \%)$ and by having the student "teach" other students $(80 \%)$.

\subsection{The construction of knowledge}

In recent years, different scholars (Niemi, 2002; Boekaerts et al., 2000; Simons, 1997 in Niemi, 2002, Bales, 1996; Wright et al., 1994; Gardner, 1991) have increasingly questioned the traditional teaching paradigm, proposing a new role for both teachers and students in acquiring knowledge. The new paradigm highlights the need of "teaching according to how students learn" (Biggs and Tang, 2007). The main underlying argument of this new paradigm is that the process of learning occurs through action: "the human mind emerges and exists as a special component of interactions with the environment, so activity (sensory, mental, and physical) is a precursor to learning" (Johnassen and Rohrer-Murphy, 1999). The process of learning, therefore, "is constructed as an active process in which the learner develops his or her own understanding by assembling facts, experience and practice" (Oblinger, 2004). In this paradigm, the student holds the responsibility for his/her learning (see Table 1). While the traditional paradigm only recognized the classroom experience, it is now recognized that learning occurs also in other settings and is often "social, collaborative, and peer based" (Ruben, 1999). Whereas these theories focussed on the experiencebased and social aspects of learning, Kolb (1984) argued that students do not all learn in the same way. While some may be more comfortable learning by experience, other may prefer experiments, observation or conceptualization. All four components, however, are to be activated: learning is about combining the different styles into a more comprehensive knowledge that encompasses both theory and observation, and experiences and experimentation. 
Table 1. Paradigm shift in teaching and learning theories.

\begin{tabular}{lll}
\hline & Traditional Paradigm & New Paradigm \\
\hline Philosophical foundation & Locke's Tabula rasa & Socratic Method \\
Acquisition of knowledge & Transferred & Exercised \\
Responsibility for learning & Teacher & Student \\
Teacher's role & Transfer & Facilitator/coach \\
Student's role & Acquire & Exercise \\
Relationship & Impersonal & Collaborative/social \\
Place & Classroom & Classroom and other settings \\
Time & Classroom sessions & Continuative process \\
\hline
\end{tabular}

Sources: (Oblinger, 2004; Niemi, 2002; Henschel, 1999; Ruben, 1999; Wright et al., 1994).

The emphasis on students' active role in learning is reflected by the emergence of a new pedagogical terminology. A variety of terms illustrate this new paradigm. Terms such as "authentic learning, self-directed learning, self-regulated learning, independent learning, autonomous learning, problem solving and active learning [which] have the same purpose, even though they originate from somewhat different theoretical frameworks" (Niemi, 2002).

\subsection{Activating students through simulation games}

Simulations games can overcome some of the limitations associated with more traditional learning (Ruben, 1999) and activate the learner. Simulation games as a teaching method have a long history (Greenblat, 1973). The core idea of a simulation game is that a real-life situation, event or activity is imitated. Key characteristics and processes of that situation, event or activity are mimicked through the simulation game. In this mimicry, a trade-off usually exists between the degree to which the simulation is "real" or accurate and the effort required in playing this game (Lankford and Watson, 2007; Oblinger, 2004; Thomas and Milligan, 2004).

Figure 1 presents the generic structure of a simulation game for a complex (integrated) water resources management system. Players represent actors that take management actions according to their mandate. The impact of the actions is simulated in a system model, which provides a new state of affairs in the water management system. Actors evaluate the "new" state of affairs and on the basis of this evaluation take new management actions for the next time period of simulation. Actions ideally represent the whole range of water management activities: investments, operational management, incentives and advice, licenses, etc. Actions often depend upon, reinforce or counteract each other with respect to their impact on the water management system. Specific actions may require consent and cooperation from other actors. The system model describes the natural, the infrastructural and the economic system and generates performance indicators for the functioning of the actors and the water resources system. True to water resources management, there is no optimum state of affairs that satisfies all.
This generic structure provides games the flexibility to pursue different learning objectives depending on how the simulation is organised and guided. Our experience indicates that learning objectives of simulation games generally fall into four classes. The first relates to how the (physical, institutional, economic) system works and how the system can be influenced in different ways. The second relates to understanding the position of other stakeholders by playing their role: what do others consider important; what conditions and constraints do they experience; what language do they use? The third learning objective relates to the interaction between interest groups or actors. And finally the structure allows games to experience and test new organizational and institutional arrangements, which in real life can hardly ever be done.

Activation is intrinsic in a simulation game: "individuals assume roles, act out their characters, experience the interaction and see the outcome" (Oblinger, 2004). Simulations allow for testing the knowledge acquired through a practical use of the knowledge. Practice through "reinforcement, application, repetition, and often practice in a variety of settings" (Ruben, 1999) enforces the knowledge.

Although simulation games clearly alter the teacherlearner relationship, teachers have not become obsolete: "it is not sufficient to provide learners with simulations and expect them to engage with the subject matter and build their own understanding by exploring, devising and testing hypotheses" (Thomas and Milligan, 2004). Simulations require feedback and support from the teacher. The role, however, shifts from transferring knowledge to facilitating knowledge acquisition or creation by the participants. Wright et al. (1994) have suggested that the role of the teacher is to act as a "coach" that monitors and regulates the learner's performance. This act of monitoring and regulating the learner's performance requires both considerable knowledge and experience on the part of the teacher as well as significant time inputs. If this required input is added to the time requirements for developing and updating the simulation game, the overall effort required to run a simulation game is often greater than requirements for traditional lecturing. 


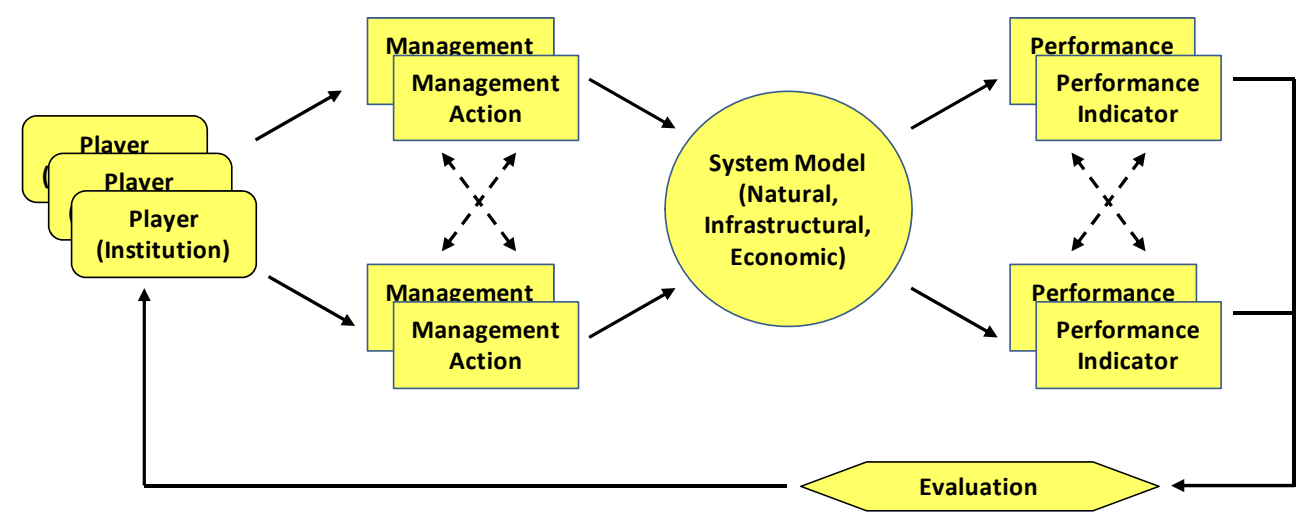

Fig. 1. Typical structure of a water management system simulation game.

\section{Changing demands for water management graduates}

The change in the teaching-learning process is not only the result of a pedagogic paradigm shift in the supply-side of higher education. The need or demand for new teaching approaches also reflects changes in the demand side of higher education with respect to water management. Essentially, three important changes in governance arrangements and in the water sector have considerable consequences for water management programmes. These changes are the increasing emphasis on IWRM as the guiding paradigm according to which water resources should be managed, the characteristics of reforms in the public sector and the shifting statesociety relations in many countries. These three factors are elaborated upon below.

\subsection{From the hydrological mission to integrated water resources management}

The emergence of Integrated Water Resources Management (IWRM) as a hegemonic paradigm in the water sector has been described and analyzed at length (Biswas, 2004; Conca, 2006; Molle, 2008, 2009; Mollinga, 2008). IWRM broadly incorporates three "systems": the bio-physical system, the infrastructural system and the organizational/institutional system. The underlying concept of IWRM is that it integrates these three systems. As such, IWRM implies an interdisciplinary approach to water resources management and requires the ability to negotiate, discuss and reach a crosssectoral consensus (Hoeskstra, 2012; Seibert and Vis, 2012). In this context, extensive knowledge and expertise in one discipline is not sufficient. For the educational sector, this implies a new approach to water management, "now recognized as a socio-economic, institutional, and ethical challenge as much as it is a biophysical and engineering challenge" (Kirshen et al., 2004). The goal of water management programs thus becomes training students with different backgrounds into experts in their field, but who also have the ability to understand and interact with other disciplines and interests (Kirshen et al., 2004).

\subsection{The speed and space of change}

Another important factor is the spatial-temporal scales at which changes are taking place in the public sector and in civil society. Globally the public sector has increasingly been subject to reforms. The pace and scope of these changes to state's structures and dynamics have become much greater than previously experienced (Thynne, 2000). Not only do changes occur more rapidly, also the governance structures have become much more complex as a shift has taken place to "governance-beyond-the-state". This shift concerns the "emergence, proliferation and active encouragement [...] of institutional arrangements of "governing", which give a much greater role in policy-making, administration and implementation to private economic actors on the one hand and to parts of civil society in the other in self-managing what until recently was provided or organized by the national or local state" (Swyngedouw, 2005). This proliferation of agencies and actors involved in water management has greatly increased the need for coordination.

In addition to the increased speed of change, also the interaction of changes at different spatial levels (global, national, local) has impacted the water sector. Changes occur rapidly at the global and the local scale. Globalization occurs at the same time as structural and organizational changes at national and local levels (Oskam, 2009; Wright et al., 1994). The water sector has not been an exception to this development. Water agencies and organizations, for instance, have moved away from hierarchical structures towards a flat type of organization, with more responsibilities assigned to teams or autonomously operating units. These reforms, in turn, demand professionals with a whole set of new abilities, such as working in teams and building consensus, critical thinking and problem solving, and cross-functional communication (Wright et al., 1994). 
Table 2. Actors and their objectives in the Ravilla simulation game.

\begin{tabular}{ll}
\hline Actors & Objective \\
\hline Water Authority (WA) & Sustainable development and efficient use of resources \\
City Water Supply Utilities (WSU) & $\begin{array}{l}\text { Efficient and sustainable service delivery of water } \\
\text { supply and sanitation }\end{array}$ \\
& Agricultural production and family income \\
Farmers (F) & Efficient management of irrigation water delivery \\
Farmers Association (FA) & Maximum industrial production and profit \\
Agro-Industry (AI) & Conserve and protect environmental resources \\
Environmental Protection Agency (EPA) & Coordination between institutions \\
River Basin Council (RBC) & Economic and social development \\
National Water Council (NWC) & \\
and Central Government (CG) & \\
\hline
\end{tabular}

Note: depending on the chosen institutional arrangement, the setting of national policies and regulations may be with the CG/NWC or the RBC or be delegated to the WA as the custodian of the water resources.

\subsection{Impact of the changes for higher education and the role of simulation games}

The impact of these changes has been to place new demands on the knowledge, skills and competencies of graduates of water programmes. Professionals in the water sector are increasingly required to be a specialist in their own field or discipline, whilst also having a "basic knowledge of adjacent and connecting fields" (Oskam, 2009). With the vertical leg of the letter "T" representing the in-depth knowledge of the main discipline and the horizontal leg of the "T" reflecting the basic knowledge of adjacent disciplines, this type of graduate has been referred to as the T-shaped graduate (Oskam, 2009). Besides the know-how, the "new" water manager also requires certain skills such as the ability in research, working in teams, "creative thinking, communication, and cooperation" (Oskam, 2009). The goal, therefore, is for the students to acquire "competence - not just awareness" (Oblinger, 2004). These goals are challenging for traditional universities, which are often organized according to particular disciplines.

In creating this T-shape professional, simulation games can play a powerful role. By mimicking real-life situations, events and processes, simulation games have the potential of reflecting the complexities witnessed in actual water management. By having the participant play the role of an actor in the simulation game, he/she will experience what it is like to have to make decisions in such a complex environment. Moreover, the interdependency of actors in the simulation game will also highlight how decision-making at different spatial levels by certain actors has impacts at other spatial levels and on other actors.

\section{The Ravilla simulation game}

The Ravilla simulation game has evolved over a decade with inputs from different staff members of UNESCO-IHE and resource analysis. The main objective of the game is to give participants hands-on experience with all important aspects of IWRM. Over time, it became an instrument that addresses all of the four learning objectives mentioned in Sect. 2.1: (i) understanding the system and its management, (ii) understanding the position of others, (iii) understanding the interaction between interest groups and (iv) experiencing different organizational and institutional settings. The relative emphasis given to a particular learning objective depends on how the game is organized.

\subsection{Playing the Ravilla simulation game}

In the Ravilla simulation game, participants represent actors in the fictive Ra Basin (Fig. 2). The actors make decisions about operational water management, in which water allocation and distribution are simulated in time steps of three months. As the game progresses, players make decisions over a timespan of one year, covering a wet and a dry season. During the game, several consecutive years are played. Decisions concern the full array of water management measures: demand and supply analysis, operation and maintenance, investments, reservoir releases and gate settings, groundwater use, water and wastewater treatment, cropping patterns and agricultural inputs, pricing and financial management, standard setting, monitoring and information release. The system model generates performance indicators with respect to service delivery, economic production and income, water quantity and quality, water shortages and losses, and efficiency and effectiveness of system management. The actors and the objectives they pursue in the game are presented in Table 2 .

The different actor groups are not homogenous. For example, the farmers are divided in small, medium or large farms. Service delivery in cities may take place through standpipes or private connections. Performances of infrastructure and distribution efficiency depend on maintenance and investments. Water quality depends upon treatment but also minimum flows. Each actor has the possibility to make 


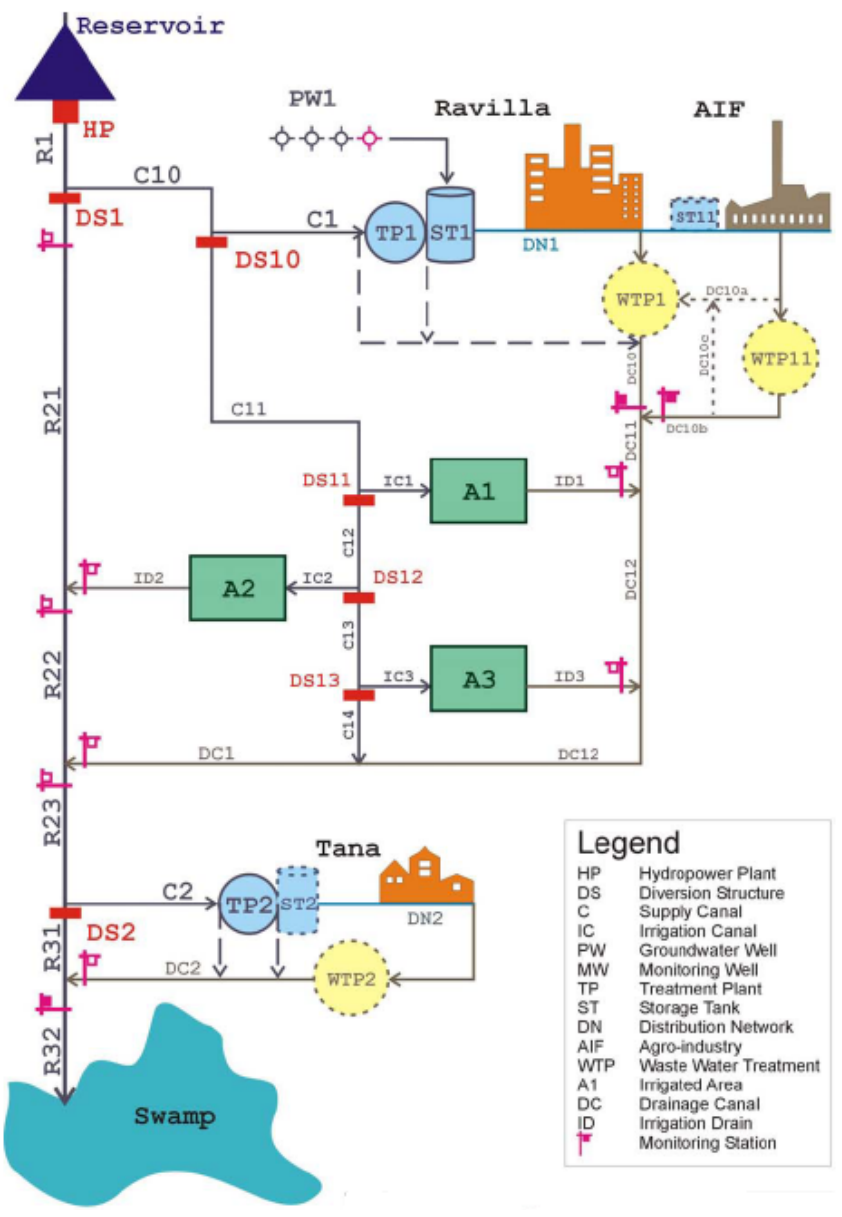

Fig. 2. Scheme of the Ra Basin.

decisions that affect water use, system performance or allocation in the basin. The combination of decisions determines the demanded amount of water by the different actors and the actual allocation of water for the different uses. This, in turn, impacts the degree to which the objectives of the actors are achieved. Given the fact that water resources are scarce within the Ra Basin, participants are stimulated to negotiate with each other regarding water demand, system operation and allocation with the aim of achieving their respective objectives.

The Ravilla game can be played using three different institutional settings (Table 3). Each setting represents different approaches to how the water sector is organized. The institutional settings vary according to the level of (de)centralization, private sector involvement, level of cost recovery, level of integration and legal framework. In each setting, the mandates of the organizations/actors are different. The idea of these multiple institutional arrangements is to highlight how reforms can affect the management of water resources and impact the different actors.

In 2012, the Ravilla game was further elaborated to incorporate an option of a transboundary water sharing dimension.
This added dimension fortified the activity of negotiation between actors by introducing international negotiations as part of the simulation game.

Playing the Ravilla simulation game essentially consists of 4 phases, which are repeated over the game's duration. First of all, the players are to undertake a situational analysis on the basis of available data. The available data, like in reallife, are limited. These data are provided to all participants in a lecture. The second stage of the game sees the participants deliberate about measures to be undertaken. Preferences for measures will be based on the situational analysis. This phase may be characterised by intensive interaction between the participants, depending upon how much the actors wish to cooperate (or consult each other). The measures that are agreed upon are then fed into the model of the simulation game in the third stage. This produces new data, which the participants then have to analyze. This final phase of analysis on the one hand seeks to understand how the selected measures have affected the situation (reflection). On the other hand, this analysis is to establish the "new" situation that forms the basis for the second round of decision-making. Our experience is that, in the course of consecutive rounds, the consultation and negotiation between actors increase as participants better understand the need for this interaction with other actors. By going through this process multiple times, the simulation game incorporates a trial and error process, which allows for participants to learn from earlier decisions, how their decisions link with decisions of other actors and the outcomes that this aggregation of decisions leads to.

At the conclusion of the simulation game, a debriefing session is held with the participants. During this session, participants present their experiences and observations on the performance of the water resources system and the water management process, and discuss the interlinkages between the bio-physical, the infrastructural and the organizational/institutional systems. The participants are asked to relate their experience of the simulation game to theoretical approaches to integrated water resources management and to their own work experience. In addition, facilitators provide feedback to the participants regarding the negotiations, decisions and the resulting outputs. By having this reflection on the simulation game, the participants are able to evaluate the negotiations and decisions they made. Moreover, this reflection deepens the understanding of integrated water management systems and processes and the relevance and irrelevance of different performance indicators.

\subsection{Lessons learnt from the Ravilla simulation game}

Based on the experience of delivering the Ravilla game over the past years in different settings, a number of general lessons can be distilled. First, the fact that the Ra Basin concerns a "fictive" case allows for students to separate themselves from their own work environment. This makes it easier 
Table 3. Characteristics of institutional arrangements represented in Ravilla simulation game.

\begin{tabular}{llll}
\hline Classification & Setting 1 & Setting 2 & Setting 3 \\
\hline Level of decentralization & Centralised & Decentralised & Partly decentralized \\
Level of private sector involvement & Public & Private & Mixed \\
Requirement of cost recovery & Low & High & High \\
Integration and coordination & No & Partly & Yes \\
Legal framework & Poor & Fair & Strong \\
\hline
\end{tabular}

to assume the different roles in the simulation game and also allows the participant to be more creative and less constrained by routinized decision-making. Also, when participants come from the same real-life work environment, then the fictive case will help to diminish hierarchical relationships which may exist in the group.

Secondly, one of the most challenging aspects of a simulation game is to ensure a proper balance. This balance is twofold. First, the game should, on the one hand, be sufficiently detailed, realistic and recognizable to give the participant the impression that the game is "real" or at least convincing. On the other hand, the game should be sufficiently simple and easy to limit the required time for understanding and playing it. Usually, between three and five days are needed to play the Ravilla simulation game properly (including students' presentations and analysis of how decisions have lead to certain outcomes). What the game must also offer is a balance between conflicts and contestation, whilst also allowing for decisions that produce "more favourable" outcomes. The participant should have the conviction that, by analyzing and understanding the decisions and the accompanying outputs, they will be able to arrive at better-informed decisionmaking. Important in this respect is also that the outcomes of the model are credible, meaning that decisions lead to understandable effects.

Thirdly, our experience is that the foundation of a successful simulation game is the face-to-face interaction of players. Although the computer-based model plays an important role in translating decisions by the players to a new situation, the model should not become the focal point of the game. Ideally, the use of computers by participants should be limited to a minimum. Rather, the simulation game works best when it adheres to paper-based decision-making and output mechanisms (through standardized forms). Use of the computer to run the model is limited to the main facilitator. Having the participant use a computer usually distracts the participant from face-to-face interaction and discussion with other participants. Moreover, it steers the game too much to a discussion on the model rather than to stimulate understanding the bio-physical, infrastructural and institutional systems. In this sense, a water resources management simulation game differs from decision support systems (DSS) or expert systems for water resources planning and management. These DSS almost always lack the essential elements of simulation games for understanding IWRM: the process of decision-making and the interaction with other stakeholders. Moreover, these tools encompass only a distant rather than a real confrontation with trade-offs inherent to IWRM.

Fourthly, the feedback from participants is that they are able to identify with the actors they represent. Moreover, during the game participants truly become concerned about their roles. In addition, during the game they truly become concerned about their function. The reason is that Ravilla offers a good mix of operational management and policy development in which students have to live with decisions made in previous rounds, but also feel that they can influence the state of affairs in very realistic ways.

An important added value of the Ravilla simulation game, and one that we feel should apply to all simulation games, is that it is embedded in a broader conceptual framework. In the case of Ravilla, this broader framework is that of integrated water resources management. The game exposes the difficulties and challenges in pursuing integrated water management. The simulation game must thus be seen as a complement to other educational activities in which this conceptual frame is presented and discussed in detail. Important in this respect is that simulation game must highlight salient features of that broader conceptual framework. In Ravilla, this is achieved through the inclusion of different sectors (environmental and civil society) and allowing for different institutional arrangements, which illustrate how reforms may impact decision-making and different actors.

\section{The potential and limitations of simulation games}

In this article, we have argued that using simulation games can contribute to the learning experience of students in the field of water management. The potential of simulation games, however, is strongly dependent on the context in which it is implemented and is subject to limitations. This potential and limitations are elaborated upon below.

The emergence of a new paradigm on learning and the construction of knowledge has favoured experienced-based tools. These are seen as allowing for more in-depth and long-term knowledge acquisition. If well designed, simulation games can offer an important opportunity for experiencing a multidisciplinary scenario in a "protected" and controlled environment. Whilst many educational programmes are monodisciplinary, the labour market requires flexible, "tshaped" professionals. The simulation offers an opportunity 
to integrate various disciplines by combining technical fields such as hydrology and water resources management (e.g. water allocation, dams, hydropower generation, irrigation systems etc.) with socio-economic disciplines. The simulation allows for repetition (trial and error) and, as such, reinforcement of knowledge acquisition. The game can also be adapted to new scenarios, reflecting the shifting emphasis within the water sector. Further, it allows a participant to experience beyond one's established reality, by offering a flexible systems that can be modified and adapted through fictive reform processes, development of policies, or the introduction of hydrological changes (e.g. droughts, floods, over abstraction of groundwater). Simulations bring participants to a table to negotiate and build consensus within the group and with other groups. Players will directly experience the different power status of the stakeholders, the control certain stakeholders (unlike others) have over strategic resources and the informal influence of the stakeholder (personal relations, networks, leadership etc.). Moreover, simulations stimulate interaction of participants by forcing players to work in a team and build consensus on certain measures/decisions within the simulation. At the same time, simulations also reflect imbalances that participants will also experience in their daily professional life. Some participants will have stronger leadership skills, have more knowledge or ability to analyze a given situation or will be better negotiators. The outcome of the simulation will largely depend on these factors.

At the same time, the simulation game also has its limits. Simulation games may not be more efficient than other teaching methods. In fact, our experience is that simulations increase the demands placed on teachers rather than reduce them. The role of the teacher changes from transferring knowledge to that of facilitating knowledge construction. This requires considerable knowledge and experience. The teacher must analyze and interpret how the game is proceeding, steer and guide the game during its implementation, and finally assist the players in the reflections on their decisions and the game in general. Moreover, preparation time, participation in the simulation and in the analyses that (should) follow the exercise mean that the effort required on the part of the teacher is significant. If the simulation aims at promoting multidisciplinarity, facilitators need to develop themselves as a T-shaped lecturer, before being able to guide students in this process. The fact that simulation games usually require periodic updating to accurately reflect current trends in the water sector increases knowledge and time-requirements for implementing such educational tools. Moreover, the simulation game is ideally part of a larger blended learning activity. Finding the right balance between different learning activities (and the contributions they provide for constructing knowledge) is crucial. Before deciding on using a simulation game, these issues need to be carefully addressed.

Edited by: J. Seibert

\section{References}

Bales, E.: Corporate Universities versus Traditional Universities: Friends or Foes. Key Note Address at the Conference on Innovative Practices in Business Education, Orlando, FL, 4-7 December, 1996.

Biggs, J. B. and Tang, C.: Teaching for quality learning at university, Open University Press/Mc Graw-Hill Education, 2007.

Biswas, A. K.: Integrated Water Resources Management: a Reassessment, Water Int., 29, 248-256, 2004.

Boekaerts, M., Pintrich, P. R., and Zeidner, M. (Eds.): Selfregulation: Theory, research, and applications, Orlando, FL, Academic Press, 2000.

Conca, K.: Governing water: contentious transnational politics and global institution building, MIT Press, Cambridge, 2006.

Dale, E.: Audiovisual methods in teaching, 3rd Edn., The Dryden Press, New York, 1969.

Gardner, H.: The Unschooled Mind, New York: Basic Books, 1991.

Greenblat, C.: Teaching with simulation games: A review of claims and evidence, Teach. Sociol., 1, 62-83, 1973.

Henschel, P.: The manager's core work in the new economy, http: //www.newmango.com/01iftf/henschel.html (last access: 20 January 2012), 1999.

Hoekstra, A. Y.: Computer-supported games and role plays in teaching water management, Hydrol. Earth Syst. Sci. Discuss., 9, 1859-1884, doi:10.5194/hessd-9-1859-2012, 2012.

Johnassen, D. H. and Rohrer-Murphy, L.: Activity theory as a framework for designing constructivist learning environment, Etr. \& D.-Educ. Tech. Res., 47, 61-79, 1999.

Kirshen, P. H., Vogel, R. M., and Rogers, B. L.: Challenges in graduate education in integrated water resources management, J. Water. Res. Pl.-ASCE, Editorial, 185-186, 2004.

Kolb, A. D.: Experiential learning: Experience as the source of learning and development, Prentice Hall, Englewood Cliffs, NJ, 1984.

Lankford, B. A. and Watson, D.: Metaphor in natural resource gaming; insights from the River Basin Game, Simulat. Gaming, 38, 421-442, 2007.

Molle, F.: Nirvana concepts, narratives and policy models: Insights from the water sector, Water Alternatives, 1, 131-156, 2008.

Molle, F.: River-basin planning and management: The social life of a concept, Geoforum, 40, 484-494, 2009.

Mollinga, P.: Water, politics and development: Framing a political sociology of water resources management, Water Alternatives, 1, 7-23, 2008.

Niemi, H.: Active learning-a cultural change needed in teacher education and schools, Teach. Teach. Educ., 18, 763-780, 2002.

Oblinger, D.: The next generation of educational engagement, Journal of Interactive Media in Education, 8, 1-18, 2004.

Oskam, I. F.: T-shaped engineers for interdisciplinary innovation: An attractive perspective for young people as well as a must for innovative organisations, public lecture given in Amsterdam, 11 March, 2009.

Piaget, J.: The Psychology of Intelligence, Routledge, New York, 1950.

Plato: Meno, great dialogues of Plato, Mentor, New York, 28-69, 1956.

Ruben, B. D.: Simulations, games, and experience-based learning: The quest for a new paradigm for teaching and learning, Simulat. Gaming, 30, 498-505, 1999. 
Seibert, J. and Vis, M. J. P.: Irrigania - a web-based game about sharing water resources, Hydrol. Earth Syst. Sci. Discuss., 9, 1961-1977, doi:10.5194/hessd-9-1961-2012, 2012.

Swyngedouw, E.: Governance innovation and the citizen: the Janus face of governance-beyond-the-state, Urban Stud., 42, 19912006, 2005.

Thomas, R. C. and Milligan, C. D.: Putting teachers in the loop: Tools for creating and customising simulations, Journal of Interactive Media in Education, 15, 1-22, 2004.
Thynne, I.: The state and governance: issues and challenges in perspective, Int. Rev. Adm. Sci., 66, 227-240, 2000.

Wright, L. K., Bitner, M. J., and Zeithaml, V. A.: Paradigm shifts in business education: Using active learning to deliver services marketing content, Journal of Marketing Education, 16, 5-19, 1994. 